ISSN 1981-416X

Licenciado sob uma Licença Creative Commons

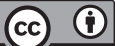

\title{
Educação híbrida e design instrucional: estudo de caso no Ensino Superior Tecnológico
}

\author{
Blended learning and Instructional Design: \\ case study in Technologic Higher Education
}

Enseñanza híbrida y diseño instruccional: estudio de caso en la Educación Superior Tecnológica

\author{
Adriane Belluci Belório de Castro ${ }^{[a]}$, Daniel Mill ${ }^{[b]^{*}}$ \\ [a] Faculdade de Tecnologia de Botucatu, Botucatu, SP, Brasil \\ ${ }^{[b]}$ Universidade Federal de São Carlos, São Carlos, SP, Brasil
}

\section{Resumo}

Em um cenário em constante transição, um dos desafios vividos, atualmente, no âmbito educacional, é o que envolve o planejamento e a construção de modelos de design instrucional compatíveis às emergentes necessidades de aprendizagem do aluno em qualquer nível de formação, seja básico, seja superior. Assim, com o intuito de experimentar um ambiente em que se tem a implementação de princípios da educação híbrida, este artigo tem por objetivo apresentar um estudo de caso em que se planejou e aplicou uma proposta de design instrucional, com ênfase na utilização de inovações e aplicações tecnológicas 
como apoio a aulas presenciais, para a disciplina de Comunicação e Expressão em um curso superior tecnológico público.

Palavras-chave: Aplicações tecnológicas. Aprendizagem. Inovações educacionais.

\begin{abstract}
In a scenario in constant transition, one of the challenges currently faced in the educational sphere is what involves planning and constructing instructional design models compatible with the emerging learning needs of the student at any level of training, whether basic or superior. The aim of this article is to present a case study in which an instructional design was planned and implemented, with the emphasis on the use of innovations and technological applications as support for face-to-face classes, for the subject of Communication and Expression in a public technological higher education course.
\end{abstract}

Keywords: Technological applications. Learning. Educational innovations.

\title{
Resumen
}

En un escenario en constante transición, uno de los desafíos vividos, actualmente, en el ámbito educativo, es lo que implica la planificación y la construcción de modelos de diseño instruccional compatibles con las emergentes necesidades de aprendizaje del alumno en cualquier nivel de formación, sea básico, sea superior. Así, con el propósito de explorar un ambiente en que se tiene la implementación de principios de la enseñanza híbrida, este artículo tiene por objetivo general presentar un estudio de caso en que se planificó y aplicó una propuesta de diseño instruccional, con énfasis en la utilización de innovaciones y aplicaciones tecnológicas, com el fin de apoyar las clases presenciales en la disciplina de Comunicación y Expresión en un curso superior de tecnología público.

Palabras clave: Aplicaciones tecnológicas. Aprendizaje. Innovaciones educativas. 


\section{Introdução}

Há algum tempo, tem-se observado a necessidade de remodelar o ensino presencial tendo como parâmetro atrativos comparáveis aos do ensino a distância, que tem se expandido continuamente, graças a inovações tecnológicas que se atualizam constantemente. Para tanto, é preciso sair do lugar comum da sala de aula (giz, lousa, voz e exibição de slides) e potencializar didaticamente o uso das tecnologias digitais de informação e comunicação (TDIC), de tal forma que sejam exploradas metodologias ativas. Assim, promove-se mobilidade e personalização para o processo de aprendizagem, de modo que professor e aluno possam expandir as possibilidades de atividades, diversificar métodos e ampliar tanto a interação entre si quanto com os conteúdos abordados.

Considera-se que "a mobilidade, a personalização da aprendizagem e o modelo híbrido (presencial e on-line) - já praticados nos cursos de educação a distância - devem ser levados aos programas de ensino básico. A escola, ou parte dela, vai caber nos dispositivos móveis" (BATISTA, 2016). Esse retrato, desenhado na reportagem especial feita pelo jornal Folha de São Paulo em 29 de julho de 2016, aponta para a direção que os pesquisadores têm seguido quando o assunto é a influência e participação tecnológica na Educação.

Assim, o desafio que se tem é, ao mesmo tempo, o de preparar professores e educar alunos para o uso de tecnologias digitais disponíveis atualmente e para as que hão de surgir. Do mesmo modo, há, também, outros desafios, como a elaboração de materiais educativos digitais e a proposição de modelos de design educacional compatíveis às emergentes necessidades de formação do aluno em seu nível educacional quer básico, quer superior.

Nesse contexto, este artigo apresenta inovações pedagógicas organizadas como proposta-piloto de um design instrucional para a disciplina de Comunicação e Expressão no ensino superior tecnológico, com ênfase na utilização de TDIC como apoio a aulas presenciais, a partir de um estudo de caso junto a alunos de um curso superior tecnológico público. 


\section{Educação híbrida e design instrucional}

Ainda com certa resistência, a inovação pedagógica por meio das TDIC está alcançando o ambiente escolar e adentrando as salas de aula do ensino presencial. Isso tem acontecido, na atualidade, de forma ainda bastante pontual e fragmentada, principalmente quando consideramos o contexto educacional público. Entretanto, não é mais possível ficar alheio à utilização dessas tecnologias que de ferramentas passaram a desempenhar um papel fundamental e de destaque no processo educacional.

Nesse sentido, há de se pesquisar e desenvolver projetos que contemplem o planejamento e desenho de disciplinas e cursos do ponto de vista das inovações tecnológicas com implicações em inovações pedagógicas. Desse modo, o leitmotiv deste trabalho incide sobre os seguintes fundamentos teóricos: educação híbrida com foco tecnológico e design instrucional.

Uma das mais recentes perspectivas de se trabalhar com as TDIC em sala de aula e ao mesmo tempo propiciar uma transformação metodológica no ensino é por meio do denominado blended learning ou, trazendo para idioma português, educação híbrida (ou ensino híbrido, como alguns autores preferem). Embora haja certa complexidade em sua definição, o conceito de educação híbrida, cujo objetivo é desenvolver estruturas conceituais no funcionamento escolar para uma educação mais atraente para os alunos que possibilite um processo mais efetivo e desperte maior interesse no aprendizado, pode ser entendido como uma proposta de ensino-aprendizagem que mescla ou combina o melhor da escola tradicional com o poder transformador da aprendizagem on-line (MILL; CHAQUIME, 2017).

Dessa forma, destacamos que:

Ensino híbrido pode ser entendido como uma interligação entre modalidades (presencial, virtual) ao longo do caminho de aprendizagem de cada aluno dentro de um curso ou de uma disciplina, a fim de proporcionar uma experiência integrada de aprendizagem, de modo que o aluno possa, de alguma forma, ter controle sobre espaço, tempo 
e ritmo e esteja no centro do processo de aprendizagem (BACICH; TANZI NETO; TREVISANI, 2015).

Em sentido amplo, educação híbrida tem sido definida como a combinação das modalidades de educação presencial com a educação a distância. Entretanto, quando se combina algo, há que se observar certas particularidades, como por exemplo, há pessoas que se referem à educação híbrida como educação semipresencial, mas essas duas configurações não são a mesma coisa.

De acordo com Bacich, Tanzi Neto e Trevisani (2015), educação híbrida refere-se a uma abordagem pedagógica que aproxima e une atividades presenciais e atividades realizadas por meio das TDIC. Para os autores, existem diferentes propostas de como combinar essas atividades, porém, na essência, a estratégia consiste em colocar o foco do processo de aprendizagem no aluno, e não mais na transmissão de informação que o professor tradicional realiza.

Complementarmente, outra definição pode ser aqui agregada:

Ensino híbrido é qualquer programa educacional formal no qual um estudante aprende, pelo menos em parte, por meio do ensino on-line, com algum elemento de controle do estudante sobre o tempo, o lugar, o caminho e/ou o ritmo do aprendizado (HORN; STAKER, 2015, p. 34).

Horn e Staker (2015) apontam, ainda, quatro formas de organização (modelos) de educação híbrida, que têm se destacado em meio ao que eles designaram como primeiros estágios de desenvolvimento dessa forma de ensino: modelo de rotação; modelo flex; modelo à la carte e modelo virtual enriquecido. Por outro lado, tais autores explicam que outras formas de organização de educação híbrida parecem ser disruptivos em relação às salas de aula tradicionais. Eles não incluem a sala de aula tradicional em sua forma plena; apenas mostram os benefícios desta sala, de acordo com uma nova definição do que é bom, e ainda o que tende a ser mais difícil para se adotar e operar nesse espaço tradicional de aprendizagem.

Como prática didático-pedagógica, a adoção da metodologia híbrida tem como finalidade a promoção da aprendizagem autônoma relacionada 
à experiência e ao incentivo à educação permanente por meio de um ensino de qualidade. Somando-se às explicações sobre educação híbrida,

o blended learning não se restringe apenas à conjugação do ensino presencial ao ensino a distância; esse conceito ainda pode congregar a mescla de variados recursos tecnológicos e também a combinação de diferentes métodos de ensino-aprendizagem (RODRIGUES, 2010, p. 9).

No entanto, é necessário ressaltar que a educação híbrida não é simplesmente a junção de educação presencial com educação a distância $(\mathrm{EaD})$, sem critérios nem planejamento. Ao invés disso, é preciso que haja organicidade na articulação entre atividades presenciais e virtuais com vistas à implantação de metodologia híbrida, de tal modo que se destaquem as vantagens pedagógicas de ambas as modalidades, garantindo, assim, maior qualidade na aprendizagem (MILL; CHAQUIME, 2017).

Nesse contexto, a combinação de elementos típicos da EaD com as atividades em sala de aula deve ser, ainda segundo Mill e Chaquime (2017), pautada por reflexões pedagógicas e adoção de metodologias que explorem mais a autonomia e liberdade dos estudantes, proporcionando, até certo ponto, uma personalização do ensino-aprendizagem.

Como argumenta Moran (2015),

São muitas as questões que impactam o ensino híbrido, o qual não se reduz a metodologias ativas, ao mix de presencial e on-line, de sala de aula e outros espaços, mas que mostra que, por um lado, ensinar e aprender nunca foi tão fascinante, pelas inúmeras oportunidades oferecidas, e, por outro, tão frustrante, pelas dificuldades em conseguir que todos desenvolvam seu potencial e se mobilizem de verdade para evoluir sempre mais (MORAN, 2015, p. 29).

Por trazer muitas e novas possibilidades de combinação, o foco da educação híbrida deve ser sempre o resultado da aprendizagem, considerando os alunos, a cultura, os recursos de aprendizagem, a infraestrutura eletrônica, a escala e a manutenção no desenho (design), no desenvolvimento e na oferta dos diferentes tipos de misturas (HANSEN; 
MANNINEM; TIRRMAA-ORAS, 2006 apud SIQUEIRA et al., 2014). Portanto, nesses novos cenários em transição, é necessário atentar para a visão adotada pela instituição de ensino, para a competência docente na aplicação das TDIC como forma de ensino-aprendizagem, especialmente com vistas à implantação de inovações pedagógicas e novos modelos ou referenciais didático-pedagógicos. Assim, tão importante quanto se pensar na educação híbrida é se atentar para o design instrucional.

De acordo com Filatro (2004), design instrucional é a ação institucional e sistemática de ensino, que envolve o planejamento, o desenvolvimento e a utilização de métodos, técnicas, atividades, materiais, eventos e produtos educacionais em situações didáticas específicas, a fim de facilitar a aprendizagem humana a partir dos princípios de aprendizagem e instrução conhecidos. Conforme Silveira et al. (2011, p. 77), “design pedagógico, ou design instrucional, é uma área da pesquisa educacional que estuda formas de ajudar as pessoas a aprenderem melhor". Cabe ao profissional dessa área a tarefa de planejar currículos, sugerir programas de capacitação e, ainda, desenvolver materiais didáticos em diferentes mídias e contextos de aprendizagem.

Silva e Castro (2009) afirmam que o design instrucional vem sendo considerado uma ação sistemática de planejamento, adaptações metodológicas e outras estratégias didáticas, principalmente, no tocante ao processo de construção de material didático, especialmente voltado a aplicações de inovações tecnológicas. Os autores ainda reiteram que as TDIC têm oferecido meios que facilitam o processo de educação, agregando ferramentas inerentes a qualquer projeto educativo. Como destaca Alonso (apud SILVA; CASTRO, 2009), o importante é perceber que o uso das TDIC deve buscar mapear o conjunto de tarefas e questões para a implantação e desenvolvimento dos cursos, respondendo as seguintes questões: Para quem o projeto será desenvolvido? Por que o projeto será desenvolvido? E como o projeto será desenvolvido? E é devido à utilização das TDIC que hoje a educação tem ultrapassado, eliminado ou, ao menos, minimizado distâncias geográficas e temporais. 
Nesse sentido, o design instrucional é o processo de criação de experiências de aprendizado eficazes e significativas, ao mesmo tempo em que permite, otimizar o tempo do professor, personalizar o ensino e, principalmente, captar e reter a atenção e permanência dos alunos. Portanto, o design instrucional é uma ferramenta indispensável para a implantação da educação híbrida, ou mesmo para melhor dimensionar a transposição do ensino presencial tradicional para a configuração híbrida.

\section{Proposições metodológicas}

Esta pesquisa, de caráter exploratório, classifica-se como pesquisa aplicada, tendo em vista a abrangência de estudos com finalidade de resolver problemas ou dificuldades identificadas no âmbito educacional em que estão inseridos tanto pesquisadores quanto sujeitos envolvidos (GIL, 2010).

O método empregado é o denominado pesquisa-ação, muito utilizado na área educacional. Para Thiollent (1985), a orientação metodológica da pesquisa-ação possibilita aos pesquisadores em educação condições para produzir informações e conhecimentos de uso mais efetivo a nível pedagógico, o que promoveria condições para ações e transformações de situações dentro da própria instituição de ensino.

Conforme Kemmis e Wilkinson (2002), a pesquisa-ação é uma forma de investigação amparada em uma autorreflexão coletiva pelos participantes de um grupo social, com vistas a melhorar a racionalidade e a justiça de suas próprias práticas sociais e educacionais, bem como obter o entendimento dessas práticas e de situações em que elas ocorrem. Destaca-se aqui o aspecto colaborativo dessa metodologia que, ao envolver por meio da coparticipação os sujeitos, atribui ao processo um caráter democrático e de estímulo à mudança social. A pesquisa-ação permite, ainda, superar lacunas existentes entre a pesquisa educativa e a prática docente, ou seja, entre a teoria e a prática, sendo que os resultados ampliam as capacidades de compreensão dos professores e suas práticas e por isso favorecem amplamente as mudanças. 
Com base nessa perspectiva, propôs-se uma modelagem de design instrucional piloto para a disciplina de Comunicação e Expressão de um curso superior tecnológico. Foram utilizados como instrumentos de pesquisa dois questionários. A partir do primeiro, construído e aplicado com recursos de computação em nuvem, reconheceu-se o perfil do aluno da disciplina, bem como as necessidades dos mesmos no tocante a metodologias de ensino-aprendizagem utilizadas em aulas. O segundo questionário, construído e aplicado com recursos de computação em nuvem, forneceu um feedback dos alunos em relação à organização e realização da disciplina de Comunicação e Expressão, em sua proposta de mudança e intervenção metodológica para a transposição ao modelo híbrido. Os discentes foram convidados a participar voluntariamente, sendo-lhes esclarecidos os objetivos da pesquisa por meio de um Termo de Consentimento Livre e Esclarecido. Paralelamente, fez-se a aplicação de um esboço piloto de design instrucional para a disciplina, com vistas à organização de atividades e metodologias aplicadas ao conteúdo, desenvolvido em formato híbrido.

\section{Resultados e discussão}

A realização do estudo de caso se deu com uma turma de Comunicação e Expressão, composta por 15 alunos, durante o segundo semestre de 2017. Treze alunos concordaram, voluntariamente, em responder ao primeiro questionário (sondagem) no mês de agosto de 2017; já do segundo (feedback), feito em dezembro de 2017, nove alunos participaram.

Por meio da aplicação do primeiro questionário aos alunos, obteve-se o seguinte perfil dos participantes: $53,9 \%$ estavam na faixa etária dos 17 a 20 anos; 76,9\% estavam fazendo o primeiro curso superior; e $53,9 \%$ foram aprovados em todas as disciplinas no semestre anterior.

Também com este questionário, foi sondado o grau de satisfação do aluno em relação a algumas variáveis associadas ao curso, à instituição e a aspectos pedagógicos. Investigou-se o grau de satisfação desse aluno em relação à escolha de curso; sobre sua experiência na faculdade; em relação a estratégias didáticas adotadas pelos professores; e, ainda, 
sobre a aplicação de TDIC no processo de ensino-aprendizagem pelos professores. Essas questões apresentavam valores de 1 a 5 para que os alunos escolhessem uma opção que corresponderia ao grau de satisfação em cada quesito, sendo que 1 correspondia a "totalmente insatisfeito" e 5, a "totalmente satisfeito". A Figura 1 ilustra os resultados obtidos.

Figura 1 - Grau de satisfação dos alunos

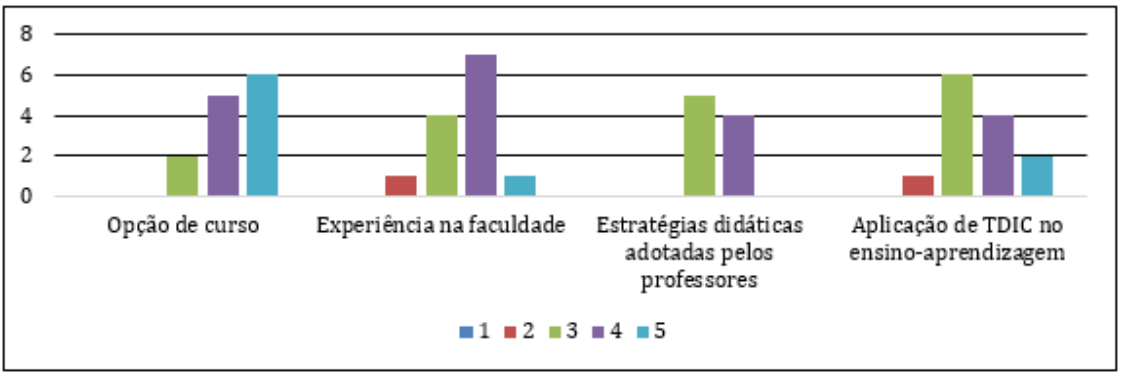

Fonte: Autoria própria.

Quando questionados sobre quais tecnologias já haviam utilizado na faculdade, a resposta dos alunos foi predominantemente: $e$-books e plataformas educacionais, conforme é evidenciado na Figura 2.

Figura 2 - Tecnologias já utilizadas pelos alunos na faculdade

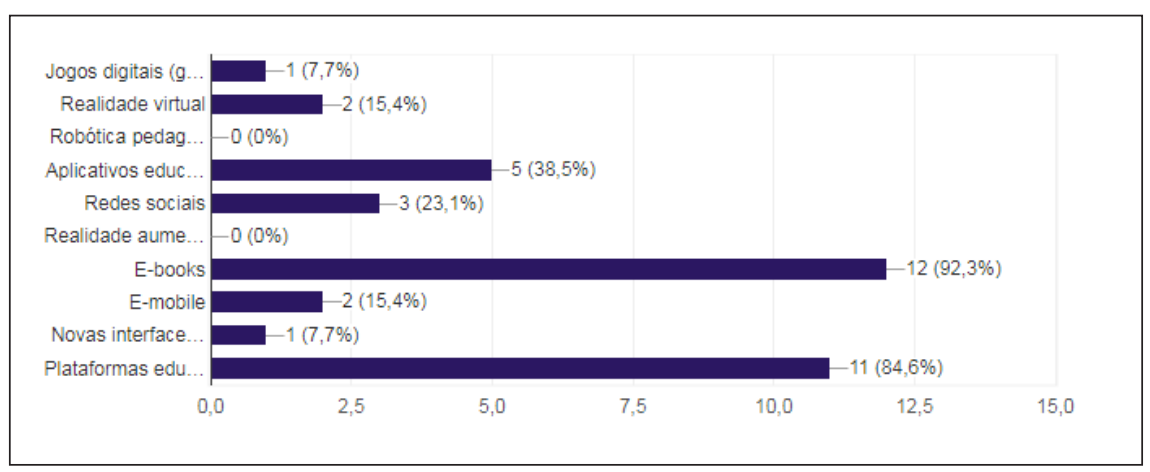

Fonte: Autoria própria. 
Finalmente, as duas últimas perguntas do questionário foram abertas e se referiam a aspectos positivos e negativos sobre o uso de tecnologias em aulas.

A questão sobre aspectos positivos obteve como resposta as seguintes considerações: aulas mais dinâmicas, grande interatividade; computadores que atendem a todos alunos; praticidade, economia de tempo, produtividade; ajudar no melhor entendimento sobre as matérias dadas; tornar mais fácil e dinâmico o aprendizado; transformar a teoria em realidade; agilidade, facilidade de entendimento; maior envolvimento dos alunos; benefícios para aprender de uma forma mais eficaz, como slide, aplicativos, sites de pesquisa, meio muito utilizado para o aprendizado, assim facilitando muito o desempenho acadêmico; maiores informações, em relação aos conteúdos; tornar mais fácil, prática e até rápida a aprendizagem; facilitar o desenvolvimento da aula.

Em relação aos aspectos negativos sobre o uso de tecnologias em aula, os alunos responderam: aluno acaba usando a tecnologia para outros fins; internet lentíssima, computadores com o SO mal instalado; falta de disciplina dos alunos; não há pontos negativos em relação a tecnologias, mas às vezes a didática de alguns professores acaba sendo ruim, mesmo utilizando ou não a tecnologia para ajudar; desatenção por parte dos alunos, ficar fazendo outras coisas ao invés do conteúdo; não há nada negativo; comodismo, falta de comprometimento; nenhum; aspectos negativos são muito poucos; os alunos se distraem muito facilmente com jogos ou redes sociais; pode criar uma dispersão na aula; tirar atenção do aluno.

Com base nesses resultados, iniciou-se, no segundo semestre de 2017, uma ação que serviu de balizamento para a modelagem de um design instrucional para a disciplina de Comunicação e Expressão, tendo em vista a utilização de tecnologias digitais e estratégias pedagógicas com ênfase na educação híbrida - proposta que pode garantir melhor nível de aprendizagem. Vale ressaltar que, nessa proposta de organização (modelagem piloto) de design instrucional, a ênfase é dada às pessoas e ao processo de aprendizagem (Quadro 1). 
Quadro 1 - Modelagem de Design Instrucional

\begin{tabular}{|c|c|c|c|c|c|c|c|}
\hline $\begin{array}{l}\text { Identificação } \\
\text { da atividade }\end{array}$ & $\begin{array}{l}\text { Nome da } \\
\text { atividade } \\
\text { (Proposta/ } \\
\text { descrição) }\end{array}$ & $\begin{array}{l}\text { Modalidade } \\
\text { da atividade }\end{array}$ & $\begin{array}{l}\text { Tipo de } \\
\text { interação }\end{array}$ & $\begin{array}{c}\text { Recurso tec- } \\
\text { nológico ou } \\
\text { ferramenta } \\
\text { a utilizar }\end{array}$ & $\begin{array}{l}\text { Frequência } \\
\text { computada }\end{array}$ & $\begin{array}{l}\text { Avaliação/ } \\
\text { valor }\end{array}$ & $\begin{array}{c}\text { Critério para } \\
\text { avaliação }\end{array}$ \\
\hline Atividade 1 & $\begin{array}{c}\text { Variação } \\
\text { Linguística } \\
\text { (Roteiro e pro- } \\
\text { dução de Vídeo } \\
\text { para apresentar } \\
\text { e ilustrar a } \\
\text { diversidade } \\
\text { linguística de } \\
\text { usos da Língua } \\
\text { Portuguesa) }\end{array}$ & $\begin{array}{l}\text { Presencial e } \\
\text { on-line }\end{array}$ & $\begin{array}{l}\text { Colaborativa } \\
\text { (em grupo) }\end{array}$ & $\begin{array}{c}\text { Câmera } \\
\text { filmadora } \\
\text { Smartphone } \\
\text { Programas } \\
\text { para edição } \\
\text { de vídeo }\end{array}$ & Não & $\operatorname{Sim}-2,0$ & $\begin{array}{l}\text { Utilização } \\
\text { de conteúdo } \\
\text { científico } \\
\text { Criação de } \\
\text { roteiro } \\
\text { Recursos } \\
\text { audiovisuais }\end{array}$ \\
\hline Atividade 2 & $\begin{array}{l}\text { Redação e cria- } \\
\text { ção de e-book } \\
\text { (Tecnologias na } \\
\text { Educação) }\end{array}$ & $\begin{array}{l}\text { Presencial e } \\
\text { on-line }\end{array}$ & Individual & $\begin{array}{c}\text { Sites espe- } \\
\text { cíficos para } \\
\text { criação de } \\
\text { e-book }\end{array}$ & Sim & $\operatorname{Sim}-2,0$ & $\begin{array}{c}\text { Estrutura de } \\
\text { livro utilizada } \\
\text { Referências } \\
\text { de pesquisa } \\
\text { Criatividade }\end{array}$ \\
\hline Atividade 3 & $\begin{array}{c}\text { Leitura de } \\
\text { textose } \\
\text { elaboração de } \\
\text { Mapas Mentais } \\
\text { (Fluxogramas) }\end{array}$ & Presencial & Individual & $\begin{array}{c}\text { Sites } \\
\text { específicos } \\
\text { para criação } \\
\text { de mapas } \\
\text { mentais }\end{array}$ & Sim & Não & \\
\hline Atividade 4 & $\begin{array}{c}\text { Dinâmicas, } \\
\text { roteiro e } \\
\text { preparo para } \\
\text { Apresentação } \\
\text { oral } \\
\text { (Comunicação } \\
\text { oral) }\end{array}$ & $\begin{array}{l}\text { Presencial e } \\
\text { on-line }\end{array}$ & $\begin{array}{c}\text { Colaborativa } \\
\text { (em grupo) }\end{array}$ & $\begin{array}{c}\text { Sites de } \\
\text { pesquisa } \\
\text { Programas } \\
\text { para } \\
\text { produção de } \\
\text { apresenta- } \\
\text { ção }\end{array}$ & Sim & $\operatorname{Sim}-2,0$ & $\begin{array}{c}\text { Escolha e } \\
\text { organização } \\
\text { do assunto } \\
\text { Postura, } \\
\text { linguagem e } \\
\text { motivação }\end{array}$ \\
\hline Atividade 5 & $\begin{array}{l}\text { Sarau de poe- } \\
\text { mas (Expressão } \\
\text { oral e corporal) }\end{array}$ & Presencial & Individual & $\begin{array}{l}\text { Sites de } \\
\text { busca e } \\
\text { pesquisa }\end{array}$ & Sim & Não & \\
\hline Atividade 6 & $\begin{array}{l}\text { Análise e pro- } \\
\text { dução de textos } \\
\text { argumentativos } \\
\text { (Argumentação } \\
\text { e Persuasão) }\end{array}$ & Presencial & Individual & & Sim & $\operatorname{Sim}-2,0$ & $\begin{array}{c}\text { Qualidade } \\
\text { do texto, } \\
\text { tendo em } \\
\text { vista o } \\
\text { gênero a que } \\
\text { pertence, } \\
\text { além de } \\
\text { aspectos } \\
\text { gramaticais e } \\
\text { formais }\end{array}$ \\
\hline Atividade 7 & $\begin{array}{l}\text { Exercícios de } \\
\text { coerência e } \\
\text { coesão textual }\end{array}$ & Presencial & $\begin{array}{c}\text { Colaborativa } \\
\text { (em grupo) }\end{array}$ & & Sim & Não & \\
\hline Atividade 8 & $\begin{array}{l}\text { Portfólio de } \\
\text { Produção } \\
\text { Textual }\end{array}$ & On-line & Individual & $\begin{array}{l}\text { Plataforma } \\
\text { Moodle e } \\
\text { liberdade de } \\
\text { escolha na } \\
\text { produção e } \\
\text { apresen- } \\
\text { tação final } \\
\text { dos textos } \\
\text { (digital, } \\
\text { impresso, } \\
\text { manuscrito } \\
\text { ou outra for- } \\
\text { ma criativa) }\end{array}$ & Não & $\operatorname{Sim}-2,0$ & $\begin{array}{c}\text { Criatividade, } \\
\text { organização } \\
\text { e quantidade } \\
\text { de textos } \\
\text { produzidos }\end{array}$ \\
\hline
\end{tabular}

Fonte: Adaptado de SANTIAGO (2017). 
Primeiramente, em agosto de 2017, estabeleceu-se um contrato pedagógico com os alunos, esclarecendo como seria realizada a disciplina, na qual seriam desenvolvidos projetos com apoio de diferentes recursos tecnológicos. Também foram estabelecidos os critérios de avaliação específicos para a produção ou realização de cada atividade, salientando o objetivo e o conteúdo a serem alcançados com cada proposta. Além disso, também foram realizadas duas provas escritas.

Ainda na primeira semana de aula, com a autorização e a anuência de todos os alunos, foi criado um grupo na rede social Whatsapp ${ }^{\circledR}$ para ampliar e agilizar a comunicação e interação entre professor e alunos, em caso de dúvida, ou mesmo para envio de textos e vídeos relacionados à disciplina. Foram passadas orientações de como se deveria comportar em um grupo nesse formato, ou seja, com finalidade educativa e postura conveniente.

Também foi apresentada e explicada a estruturação da educação híbrida adotada com ênfase em uso das TDIC, metodologias ativas e aprendizagem baseada em projetos. Características como colaboração, autonomia, curiosidade, responsabilidade, criatividade, organização e gestão do tempo, entre outras, foram dadas como virtudes a serem buscadas como alvo de formação durante a realização da disciplina.

Outro diferencial na composição das aulas (este agora trazido da gamificação) foi o fato de se ter estimulado a criação de equipes de trabalho, as quais tiveram de produzir uma identidade por meio de um nome que acompanharia cada equipe até o fim do semestre, além da designação de papéis e funções para cada integrante da equipe. Durante o semestre, com a realização das atividades, descritas no Quadro 1, foi possível acompanhar os pontos fortes e fracos de cada proposta, a fim de incorporar aprimoramentos posteriores na modelagem pedagógica originalmente desenhada.

No fim do semestre, em dezembro de 2017, por meio de um questionário com doze perguntas mistas, ou seja, questões de múltipla escolha, de caixa de seleção e abertas, solicitou-se aos alunos a apreciação da disciplina e das atividades realizadas. Desse modo, foi possível construir um feedback dos sujeitos participantes desse projeto piloto, a fim de se direcionar melhor a construção de um modelo de design instrucional para a disciplina Comunicação e Expressão, com a adoção de educação híbrida, combinando-se metodologias ativas e aprendizagem baseada em projetos.

O questionário tinha como objetivo coletar uma apreciação e um feedback dos alunos em relação à disciplina em novo formato. No total, nove alunos 
responderam ao questionário. Por este instrumento, também foi possível observar a participação ativa na disciplina de quase $90 \%$ dos alunos entrevistados.

Na Figura 3, são apresentados os qualitativos, em relação à proposta metodológica da disciplina, de maior representatividade apontados pelos entrevistados. $77 \%$ consideram a proposta diferenciada, $66,7 \%$, desafiadora e interativa e 55,6\%, inovadora.

Figura 3 - Apreciação da proposta de metodologias na percepção dos alunos

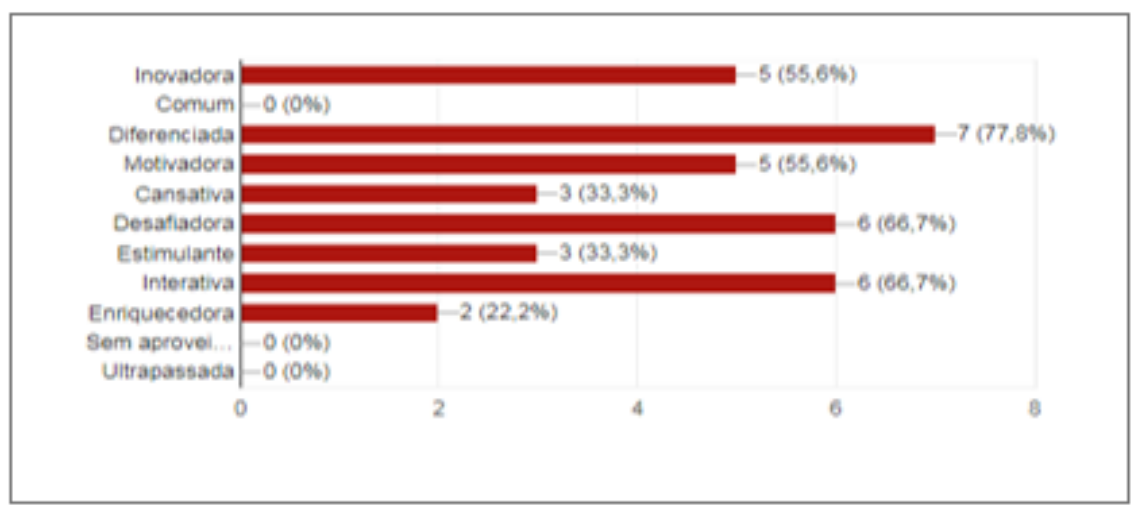

Fonte: Autoria própria.

Foi feita a classificação em ordem de preferência e importância, para os alunos, das atividades realizadas e, das dez atividades apresentadas, duas se destacaram como preferidas e importantes: a redação e criação de um e-book, utilizando uma plataforma livre, e a orientação e produção da dinâmica, planejamento e roteiro para apresentação oral. Além disso, 77,8\% dos alunos afirmaram que recomendariam a disciplina a um amigo. E, finalmente, aproximadamente $90 \%$ dos entrevistados consideram a disciplina como importante para sua formação.

De acordo com os entrevistados, oito afirmaram que o uso da rede social Whatsapp ${ }^{\circledR}$ na disciplina, de algum modo, auxiliou na interação professor-alunos, pois permitiu: melhor comunicação e esclarecimento de dúvidas; acréscimo de explicações sobre conteúdos; comunicados mais ágeis e 
compartilhamento de conteúdo adicional relacionado à disciplina; exposição de vídeos sobre os conteúdos estudados. Entretanto, um destacou que o recurso poderia ter uma sido mais utilizado para maior interação.

Ainda pela entrevista, $100 \%$ dos alunos afirmaram terem ficado satisfeitos com os métodos e tecnologias utilizadas na disciplina. Quando questionados sobre outras possibilidades de uso de tecnologias na disciplina, cinco entrevistados disseram que sim, porém somente dois apresentaram sugestões, tais como maior uso de tecnologias audiovisuais e a inserção de recursos como música. Também foi sugerido que sejam feitas mais atividades como as do sarau com o objetivo de desenvolver a comunicação oral.

Dos entrevistados, pouco mais de $77 \%$ atribuíram notas de 8 a 10 para a aplicação didático-pedagógica das tecnologias na disciplina de Comunicação e Expressão (Figura 4). Além disso, mais de 66\% afirmaram que o Laboratório de Informática é necessário para o desenvolvimento das atividades nesta disciplina.

Figura 4 - Avaliação da aplicação didático-pedagógica das tecnologias utilizadas

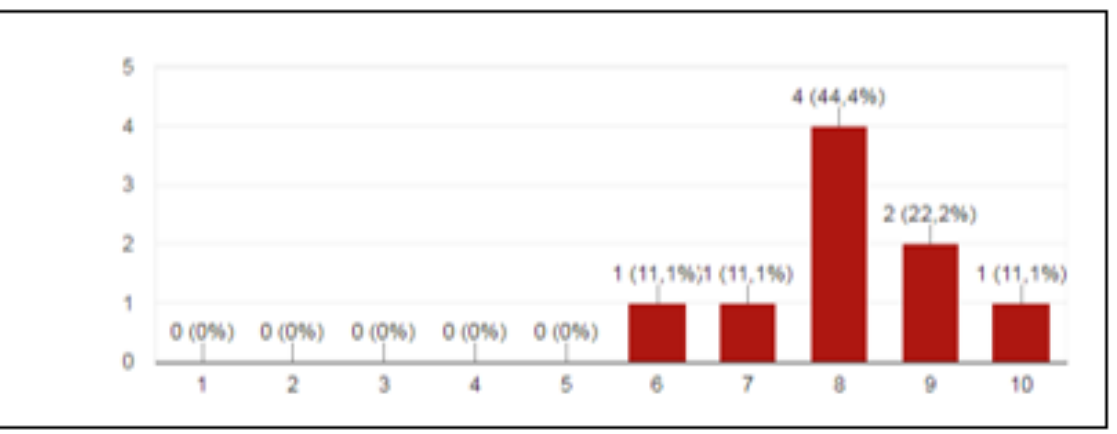

Fonte: Autoria própria.

Finalmente, quando solicitados a atribuir nota de 0 a 10 à disciplina em sua totalidade, o resultado foi coerente com as respostas dadas anteriormente, isto é, quase $90 \%$ dos entrevistados atribuíram notas de 8 a 10 , sendo que nenhum aluno avaliou com nota menor que 7, conforme Figura 5. 
Figura 5 - Representação da avaliação da disciplina em linhas gerais

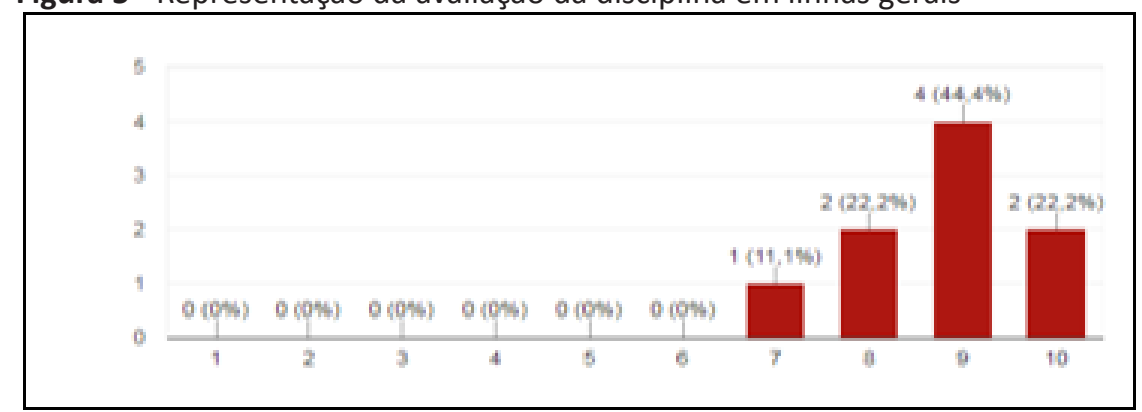

Fonte: Autoria própria.

\section{Discussão}

A partir dos resultados apresentados anteriormente, apresenta-se a discussão de aspectos que se destacaram na percepção dos alunos sobre a proposta de educação híbrida para a disciplina. Em primeiro lugar, as respostas dadas às questões abertas do primeiro questionário evidenciam que a percepção dos alunos sobre aspectos positivos do uso das TDIC em aulas corresponde ao que foi explicitado por Bacich, Tanzi Neto e Trevisani (2015), quando estes se referem à possibilidade de controle do aluno sobre espaço, tempo e ritmo de estudos, o que o coloca no centro do processo de aprendizagem.

Nesse sentido, assim como Rodrigues (2010) define, o blended learning pode ser utilizado como uma estratégia didático-pedagógica que não se configura simplesmente como um espaço aglutinador ou integrador entre as modalidades presencial e não presencial, mas como "um processo de agenciamento do sujeito do conhecimento" (RODRIGUES, 2010, p. 10). O autor ainda enfatiza que:

para que isso seja possível, é fundamental que as formas de ordenamento dos conhecimentos adquiridos no cotidiano, sobretudo no uso das tecnologias, interajam com as formas de ordenamento do conhecimento acadêmico - científico, tecnológico, enfim, de natureza epistemológica - de modo que o indivíduo possa de fato se tornar sujeito do conhecimento (RODRIGUES, 2010, p. 10). 
Outro aspecto importante, destacado pela Figura 3, evidencia que a proposta de educação híbrida é percebida pelos alunos como "inovadora, diferenciada, motivadora, desafiadora, interativa". Assim, a educação híbrida é vista como uma configuração pedagógica de maior atratividade para o aluno e capaz de despertar maior interesse na busca e construção do conhecimento por parte do sujeito do aprendizado.

Isso se coaduna ao que Mill e Chaquime (2017) consideram:

Deste modo, fica claro que nenhuma modalidade educacional ou tecnologia, por si só, promoverá mudanças no processo de ensino-aprendizagem. Antes é necessária a transformação na cultura escolar, com maior valorização de metodologias mais focadas na aprendizagem (metodologias ativas, como tem sido tratadas ultimamente). Nesse sentido, a Educação Híbrida ganha força no contexto escolar quando incorpora estratégias e tecnologias capazes de promover aprendizagens mais significativas, contextualizadas, colaborativas e personalizadas (MILL; CHAQUIME, 2017, p. 11).

E, finalmente, para que a educação híbrida produza resultados satisfatórios e desejados, é importante que seja feita a modelagem de um design instrucional, visto que este possibilita ao professor uma visão mais abrangente da contextualização, desenvolvimento e finalidade da proposta pedagógica que se intenta implantar.

\section{Considerações finais}

Os resultados obtidos neste trabalho apontam que o caminho do planejamento, desenvolvimento e modelagem de um design instrucional com ênfase na aplicação tecnológica com estratégias pedagógicas deve ser visto com bastante atenção e, ainda, incentivado de tal modo a proporcionar uma revitalização do ensino presencial tradicional, por meio da educação híbrida, e ainda garantir diferenciais no processo de aprendizagem.

É importante enfatizar, ainda, que a apreciação e feedback aqui apresentados não se referem apenas a uma ou outra atividadeisoladamente, 
mas a um conjunto de atividades planejadas, propostas, desenvolvidas e vinculadas a todos os conteúdos da disciplina de Comunicação e Expressão. Isso confirma a importância e necessidade de se refletir e modelar um desenho pedagógico para uma disciplina em um curso superior tecnológico e, até em âmbito maior, para o curso como um todo.

Por isso, a partir desse estudo de caso, sugere-se a criação de um laboratório pedagógico, em que seja motivada a troca de experiências didático-pedagógicas entre os docentes do curso, em primeira instância, e, posteriormente, a realização outras ações para a implantação de uma proposta de educação híbrida para o curso como um todo

\section{Referências}

BACICH, L.; TANZI NETO, A.; TREVISANI, F. M. Ensino híbrido: personalização e tecnologia na Educação. Porto Alegre: Penso, 2015.

BATISTA, E. L. Educação no futuro será portátil, personalizada e onipresente. Folha de São Paulo, 29 jul. 2016. Disponível em: <http://www1.folha.uol.com.br/ educacao/2016/07/1796391-educacao-no-futuro-sera-portatil-personalizada-e-onipresente.shtml>. Acesso em: 04 jan. 2017.

FILATRO, A. Design instrucional contextualizado. São Paulo: Senac, 2004.

GIL, A. C. Como elaborar projetos de pesquisa. 5. ed. São Paulo: Atlas, 2010.

HORN, M. B.; STAKER, H. Blended: usando a inovação disruptiva para aprimorar a educação. Trad. Maria Cristina Gularte Monteiro. Porto Alegre: Penso, 2015.

KEMMIS, S.; WILKINSON, M. A pesquisa-ação participativa e o estudo da prática. In: PEREIRA, J. E. D.; ZEICNHER, K. M. (orgs.). A pesquisa na formação e no trabalho docente. Belo Horizonte: Autêntica, 2002. p. 43-66.

MILL, D.; CHAQUIME, L. P. Educação híbrida como estratégica educacional. São Carlos: Editora Pixel, 2017. 
MORAN, J. Educação híbrida: um conceito-chave para a educação, hoje. In: BACICH, L.; TANZI NETO, A.; TREVISANI, F. M. Ensino híbrido: personalização e tecnologia na educação. Porto Alegre: Penso, 2015. p. 27-45.

RODRIGUES, L. A. Uma nova proposta para o conceito de blended learning. Interfaces da Educação, v. 1, n. 3, p. 5-22, 2010.

SANTIAGO, G. Ambientes virtuais de aprendizagem: uma aplicação básica no Moodle. São Carlos: Editora Pixel, 2017.

SILVA, A. R. L.; CASTRO, L. P. S. A relevância do design instrucional na elaboração de material didático impresso para cursos de graduação a distância. Revista Intersaberes, v. 4, n. 8, p. 136-149, jul./dez. 2009.

SILVEIRA, S. R. et al. Aplicação de aspectos de design instrucional na elaboração de materiais didáticos digitais para a Educação a Distância. Revista D, v. 3, p. 77-96, 2011. Disponível em: <seer.uniritter.edu.br/index.php/revistadesign/ article/download/416/258>. Acesso em: 20 out. 2017.

SIQUEIRA, A. B. et al. Mídia-educação na formação de professores: uma experiência em blended-learning. ESUD: Congresso Brasileiro de Ensino Superior a Distância, 11., 2014, Florianópolis. Anais... Florianópolis: UFSC/Unirede, p. 3386-3403, ago. 2014. Disponível em: <http://esud2014.nute.ufsc.br/anais-esud2014/files/pdf/127794.pdf >. Acesso em: 20 set. 2017.

THIOLLENT, M. Metodologia da pesquisa-ação. São Paulo: Cortez, 1985.

Recebido: 03/08/2018

Received: 08/03/2018

Recibido: 03/08/2018

Aprovado: 10/09/2018 Approved: 09/10/2018 Aprobado: 10/09/2018 